\title{
A New Year miscellany of texts
}

\section{Compiled by Helen Nield}

If you have not tried an ebook please email library@bda.org or call 02075634545 for access details. Members can read these books online at any time or download most titles for up to a week before having to download them again. Visit www.bda.org/ebooks to find all of these books and more. The library can now loan books again so contact us if you would like to borrow these instead.

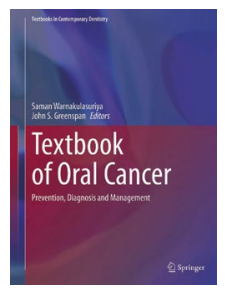

TEXTBOOK OF ORAL CANCER PREVENTION, DIAGNOSIS AND MANAGEMENT

Saman Warnakulasuriya and John S. Greenspan (Editors)

2020; Springer; 452 pp; ebook

ISBN: 9783030323158

'Recent decades have seen tremendous advances in our understanding of the etiology, biology and molecular basis of oral cancer, as well as important clinical advances in the diagnosis and management of this disease. Our aim [...] is to present important achievements [...] to summarize the current evidence, and to identify future perspectives.'

This book consists of 31 chapters plus an index and a very useful two-page list of acronyms. Its contributors come from the UK, USA, Europe, India, Australia, Japan, Israel and one of the editors is based in the UK, the other in America - so it can truly be said to be a multinational pulling together of the latest information on what is the eighth leading cause of cancer worldwide. Chapters cover, amongst other topics: epidemiology, risk factors, clinical presentation, staging, pathology, biopsies, diagnostics, screening, lifestyle interventions, factors affecting survival, cancer stem cells and debatable factors on causation. Virtually every aspect of oral cancer is looked at and the book is packed with clear diagrams, tables, and photographs. The editors of the book conclude their introduction by saying that 'The ultimate intent of the book is to have an appeal to a broad group of clinicians working in oral medicine, otolaryngology, oncology, maxillofacial pathology, and

other aspects of head and neck cancer.' https://tinyurl.com/ebooks-medprobs

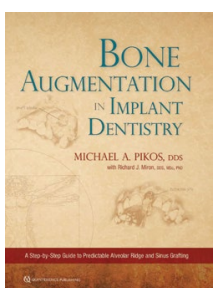

\section{BONE AUGMENTATION IN IMPLANT DENTISTRY: A STEP-BY-STEP GUIDE TO PREDICTABLE ALVEOLAR RIDGE AND SINUS GRAFTING}

Michael A. Pikos and Richard J. Miron (Editors) 2019; Quintessence publishing; 272 pp; ebook ISBN: 9780867158250

'With the number of advancements made in digitally based media and marketing, it is imperative that the clinician be able to separate new trends from evidence-based protocols $[. .$.$] we should strive to implement$ rational evidence-based decisions grounded on available literature to allow us to make sound and predictable choices. The goal of this textbook is to share my clinical experiences, both successes and failures [...] to facilitate learning through documented cases.'

The book is split into six chapters: 'Instrumentation for alveolar ridge augmentation and sinus grafting; 'Membranes, grafting materials, and growth factors'; 'Extraction site management'; 'Alveolar ridge augmentation'; 'Sinus grafting'; and 'Guided full-arch immediate-function treatment modality for the edentulous and terminal-dentition patient'. It also contains a useful index. In each of the clinical chapters a case is supplemented with the author's 'italicized personal notes' describing his own learning experiences, tips and pearls, technical notes and an in-depth analysis and critical evaluation' on how he would approach the case now. This practical text features easy to read prose and as is usual with Quintessence, excellent images. https:// tinyurl.com/ebookimplants

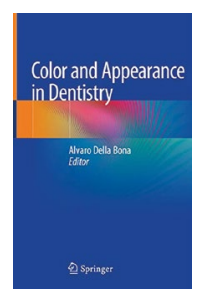

\section{COLOR AND APPEARANCE IN DENTISTRY}

\section{Alvaro Della Bona (Editor)}

2020; Springer; 142 pp; ebook ISBN: 9783030426255

'This text [...] endeavors to explain the color science and its application in Dentistry, to assist in teaching and training color determination in Dentistry, to guide on visual and instrumental dental shade matching, offering guidelines on color management and communication in Dentistry, and glancing on future developments using artificial intelligence.'

This book, edited by the experienced past president of the Academy of Dental Materials Alvaro Della Bona and written by him and a team of Brazilian dentists, takes a comprehensive look at how to get the colour right when shade matching - although it does lack an index. It uses quite technical language and goes into the science of colour in some detail. The chapter on 'Teaching and training color determination in dentistry' looks at how this art has been taught in the past as well as exploring current online methods with links to online training programmes. Shade matching is covered in both a chapter on 'visual' matching which describes the physiology of the eye in some detail and one on 'instrumental' matching. Photography is discussed in a subsequent chapter with advice on how to reproduce correct colour, complications such as colour blindness are explored in a further chapter and finally there is a description of artificial intelligence especially fuzzy systems. Each chapter finishes with a list of further reading. https://tinyurl.com/ebooks-aesth 


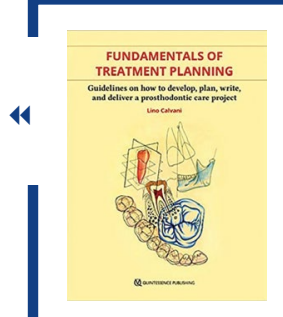

FUNDAMENTALS OF TREATMENT PLANNING: GUIDELINES ON HOW TO DEVELOP, PLAN, WRITE, AND DELIVER A PROSTHODONTIC CARE PROJECT

\section{Lino Calvani}

2020; Quintessence; 308 pp; ebook

ISBN: 9780867157925

'The complexity of the topic and the enormous body of existing literature engaged me in a great effort of synthesis to rationalize and select the fundamentals
[...] Analysis and description are the backbones of the book, and treatment planning is the basic scaffolding on which I have constructed the text.'

Professor Calvani who is currently based at Tufts University School of Dental Medicine in Boston, Massachusetts wrote this book after being asked to organise his lecture notes so that they would be accessible to all students. He believes strongly that treatment planning should be 'elevated to the same level as other scientific medical fields such as anatomy and physiology [...] It should be taught and evaluated as a subject in its own right'. The book starts with an overview of treatment planning, setting it in its historical context. Subsequently, the majority of the chapters describe different aspects of prosthodontic treatment planning and these include specific topics such as treatment planning for the elderly and planning for those with complex rehabilitations as well as general treatment planning management, prosthodontic tools for treatment planning, how to look at data, diagnosis, physical examinations, clinical examination assessment questions and a 'new and original' classification for prosthodontic treatment types. This very readable book culminates in a chapter describing how to write a prosthodontic treatment plan with an accompanying eight case presentation narrative. https:// tinyurl.com/ebooks-tplan.

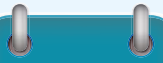
BDA AGMs

The East of Scotland Branch AGM will be held online on Wednesday 3 March 2021 at 19:00. The West of Scotland Branch AGM will be held online on Wednesday 14 April 2021 at 18:45. Please ensure you register your interest in attending either event at www.bda.org/bse in order to receive the link to access the AGM or email branchsectionevents@bda.org.

\section{Exciting study day open to all}

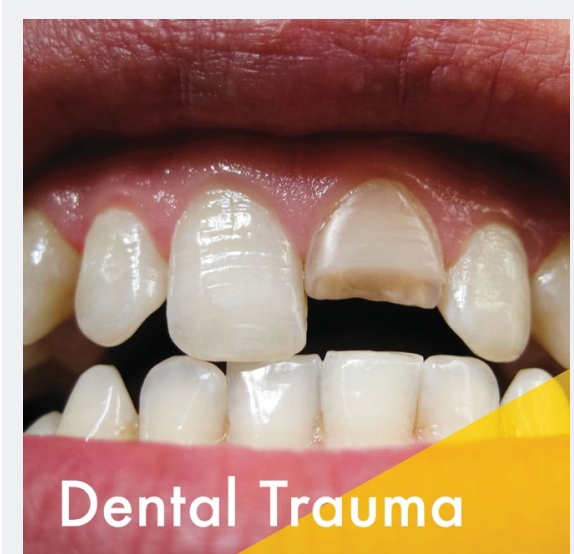

An online CPD opportunity will be held on Saturday 27 March 2021 and is open to all.

The event will be hosted by FGDP(UK) North West and broadcast live from the Science + Industry Museum, Manchester. It offers the opportunity to hear Ian Dunn and Serpil Djemal presenting Contemporary Periodontal Practice and Crash bang wallop - modern management of dental trauma, respectively.
Ian Dunn is the Perio Lead for the Faculty of General Dental Practitioners, runs their short course in Periodontics and leads the Perio components of the FGDP Restorative Diploma. His sessions will focus on Contemporary Periodontal Practice providing a modern understanding of aetiology, assessment and diagnosis, and looking at motivating patients to achieve high standards of home care to achieve non-surgical management of periodontal disease.

Serpil Djemal is actively involved in the acute and long-term management of patients who have sustained traumatic dental injuries and is also the founder chairperson of Dental Trauma UK - a new charity set up to raise public and professional awareness in the prevention and management of traumatic dental injuries. Serpil will present Crash bang wallop - modern management of dental trauma - giving all members of the dental team a better understanding of the presentation and management of traumatic dental injuries with a focus on the management of dental fractures and the management of luxation injuries.

As well as listening to the talks, delegates will have the chance to meet and chat with sponsors, other delegates and potentially the speakers, live, in a designated 'reception area' during breaks, lunch and the drinks reception.

The rates for the day are as follows: FGDP members $£ 199$, non-members $£ 299$, retired dentist/technician/ hygienist/therapist/DCP - $£ 149, \mathrm{FD} /$ $\mathrm{VDP} /$ student - $£ 30$. (Scottish dentists six hours/two sessions CPDA approved by NES.)

Attendees will earn six hours of verifiable CPD and hear world-class speakers with no travel required, networking opportunities, a 'watch again' facility online and face-to-face interaction with sponsors and suppliers.

To book a place and for updates on the timetable visit https://www.fgdp-nw.com/ book/. 